\title{
Does ketotifen have a steroid-sparing effect in childhood asthma?
}

\author{
G.J. Canny, J. Reisman, H. Levison
}

Does ketotifen have a steroid-sparing effect in childhood asthma? G.J. Canny, J. Reisman, H. Levison. (C) ERS Journals Ltd 1997.

ABSTRACT: In view of the possible systemic side-effects of inhaled corticosteroids (ICS), a study was performed to determine whether ketotifen (versus placebo) can replace or allow a reduction in the dose of ICS required for the maintenance treatment of childhood asthma.

Sixty six children (aged 6-13 yrs) with asthma (confirmed by methacholine chal-

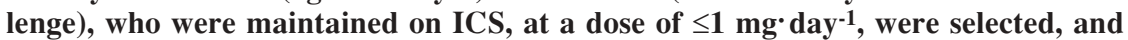
52 subjects completed the trial. Children on long-term oral steroids or cromoglycate were excluded. After a 4 week baseline period, the children were randomized to receive ketotifen, $2 \mathrm{mg}^{\cdot} \mathrm{day}^{-1}$, or placebo for 32 Weeks. Between weeks 13-20 of the study, the daily dose of steroid was tapered by $25 \%$ every second week to the minimum dose tolerated by the patients. For the remainder of the study (Weeks

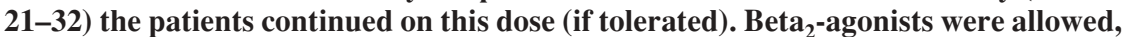
as necessary, for symptom relief

During the baseline period, the mean daily ICS dosage was $432 \mu \mathrm{g}$ in the ketotifen group versus $408 \mu \mathrm{g}$ in the placebo group (NS). Among the patients who completed the study, the average ICS dosage during the final phase of the study (Weeks 21-32) was only $18 \%$ of baseline in the ketotifen group versus $35 \%$ in the placebo group (Ns). Lung function, diurnal variability in peak flow rates and methacholine sensitivity (provocative concentration producing a $20 \%$ fall in forced expiratory volume in one second (PC20)) remained unchanged in both groups throughout the study. During the last 12 weeks of the study, the ketotifen-treated patients were symptomatically better controlled.

In the present study, ketotifen did not have a greater steroid-sparing effect than placebo.

Eur Respir J., 1997; 10: 65-70.

Based on the premise that asthma is a chronic inflammatory disease of the airways, the use of anti-inflammatory medications has assumed increasing importance in the maintenance treatment of asthma in recent years. Of these medications, inhaled corticosteroids (ICS) are the most potent and, when used regularly, provide effective control of symptoms, improve lung function, and cause a gradual reduction in bronchial reactivity $[1,2]$. Unfortunately, ICS are not completely innocuous, even at relatively small dosage $\left(\right.$ e.g. $400 \mu \mathrm{g} \cdot$ day $\left.^{-1}\right)$ [3]. Potential systemic side-effects include suppression of adrenal function, retardation of linear growth, osteopenia and decreased bone formation [1-3]. For steroid-dependent patients, therefore, ancillary treatment with a nonsteroidal prophylactic agent, which could replace ICS, at least in part, without loss of asthma control, would be a major advantage.

In this context, disodium cromoglycate has no discernable steroid-sparing effects [4]. Although the combined use of nedocromil sodium and steroids may benefit some adult asthmatics [5], this is not invariably the case [6], and withdrawal of ICS despite the concurrent use of nedocromil may lead to a deterioration in asthma control
[7]. Another alternative might be ketotifen, a nonbronchodilator prophylactic drug, which can control symptoms [8, 9], improve lung function [9] and reduce bronchodilator requirements [8] in children when used regularly for 6-12 weeks. In addition, use of ketotifen can allow a modest reduction in the need for oral steroids in adult asthmatics [10]; although, in contrast, DYSON and MACKAY [11] found that ketotifen did not have a synergistic effect with ICS in adults. The aim of the present study was to determine whether ketotifen would allow a stepwise reduction in the need for ICS in children with asthma, and prevent any subsequent deterioration in asthma control.

\section{Material and methods}

\section{Patients}

Children, aged 6-13 yrs, attending the Asthma Clinic at the Hospital for Sick Children, Toronto, were eligible to participate in the trial, provided they required continuous treatment with an inhaled steroid preparation at a dose $\leq 1 \mathrm{mg} \cdot$ day $^{-1}$ for at least 1 month and were capable 
of performing pulmonary function tests in a reliable fashion. The diagnosis of asthma was based on a compatible clinical history and the presence of bronchial hyperreactivity, as determined by a methacholine challenge test. A child whose forced expiratory volume in one second (FEV1) dropped by $20 \%$ or more from baseline in response to methacholine concentrations $\leq 25 \mathrm{mg} \cdot \mathrm{mL}^{-1}$ was considered methacholine positive.

At the beginning of the study, each patient was maintained on the lowest dose of ICS which, in the investigators opinion, was compatible with adequate asthma control. On entry to the study, patients were required to be clinically stable (with no symptoms, or only minimal symptoms responding at home to $\beta_{2}$-agonists and not resulting in school absences or the need for physician visits) for at least 1 month prior to the study, and to have FEV 1 values $>80 \%$ of the predicted normal values [12]. None of the patients had required oral steroids or used nonsteroidal antiasthma medications during the previous month. Children with underlying cardiopulmonary, hepatic or renal conditions were excluded. Written informed consent was obtained from the parents of all participants, and the trial was approved by the Human Ethics Committee of this institution.

\section{Trial design}

The study was a 36 week (four phase) randomized, double-blind, placebo-controlled study. During the initial baseline phase (Weeks -4-0), patients continued their previously established asthma treatment regimen. Provided they were stable (as defined above), children were then randomized to receive ketotifen (Zaditen ${ }^{\circledR}$ ), 2 $\mathrm{mg} \cdot \mathrm{day}^{-1}$ (given once daily as a slow-release tablet), or matching placebo for 32 weeks (both ketotifen and placebo were supplied by Sandoz Canada Inc.). From Weeks 1-12, children were maintained on their usual dose of ICS. Any child who was hospitalized or considered (either by one of the investigators or primary care physician) to require a course of prednisone during this phase was dropped from the study.

Between Weeks 13-20 of the study, the total daily dose of ICS was tapered by $25 \%$ every second week to the maximum reduction possible without a clinically significant increase in symptoms. A clinically significant increase in symptoms was defined as an increase in cough or wheeze (day or night, or with exercise) and any absence from school due to asthma. If this occurred, children were initially treated with inhaled beta ${ }_{2}$-agonists and, if symptoms were not brought under control, a burst of ICS of no longer than 7 days duration was allowed at the dose which preceded the most recent reduction. If the patient again experienced an increase in symptoms following the second attempt to reduce ICS, the previous efficacious dose (i.e. the 7 day "burst" dose) was continued until Week 32. No more than two bursts were allowed in the entire 8 week reduction phase, and these two bursts should not occur in the same reduction step. If the patient tolerated the second attempt at dose reduction, this reduced dose was continued until the next scheduled reduction. If either a course of oral steroids or hospitalization was required during this ICS reduction period, the patient was considered a treatment failure and dropped from the study.
During the follow-up phase of the study (Weeks 2132 ), patients continued on their study medications (ketotifen/placebo) and the lowest dose of ICS which was tolerated during the steroid reduction phase. During this 12 weeks, a single 7 day course of oral prednisone was permitted to control acute symptoms. If symptoms were not controlled with this therapy or hospitalization was required, the patient was considered a treatment failure and dropped from the study. Over the course of the entire study, the use of inhaled $\beta_{2}$-agonists was at the discretion of the children and parents. They were advised to seek medical attention if $\beta_{2}$-agonists were needed more than 4 hourly. Long-acting $\beta_{2-}$ agonists were not commercially available in Canada at the time of the study.

Throughout the study, parents kept daily diary cards, on which they recorded their child's use of medications, morning and evening asthma symptom scores, and peak expiratory flow rate (PEFR) values. Symptoms were scored on a four-point scale (where $0=$ no symptoms; and 3 = awake most of the night/physical activity severely limited because of asthma). The best of three PEFRs, measured using a mini-Wright meter (before use of a bronchodilator, if possible), was recorded twice daily. Peak flow diurnal variability was calculated from the difference between the highest and lowest daily PEFR, as a percentage of the highest daily PEFR.

Patients were evaluated at the clinic on eight occasions during the trial (Weeks -4, 0, 4, 12, 16, 20, 26, 32 ), when a physical examination was performed, diary cards and compliance were checked, and any adverse effects of the study medication recorded. Any patient who ingested $80 \%$ or less of the study medication (as determined by tablet count) between any clinic visits was considered noncompliant and withdrawn from the study. Forced vital capacity (FVC), FEV1, and forced expiratory volume at mid-expiratory phase (FEF 25-75\%) were measured by standard spirometric techniques [13] (at Weeks $-4,0,12,20,32$ ), and expressed as a percentage of predicted normal values [12]. A methacholine challenge test was performed on four occasions during the study (Weeks $-4,12,20,32$ ), according to the previously described methodology for this laboratory [14]. A methacholine test was completed when a 20\% decrease in baseline FEV1 occurred with one of the methacholine concentrations (provocative concentration (PC20)). Whenever possible, lung function and methacholine challenges were performed at the same time of day for each subject, and bronchodilators were withheld for $6 \mathrm{~h}$ before these tests. Routine haematology tests and biochemical tests of hepatic and renal function were performed at baseline and at the end of the study.

\section{Statistical analysis}

The primary outcome variable used to assess efficacy was reduction in ICS dosage, which was defined as the average daily dose of ICS used during the followup phase (Weeks 21-32), expressed as a percentage of the average daily dose required during the baseline phase (Week -4-0). The target sample size of this study was 31 evaluable patients per group to detect a clinically significant difference of a reduction to $80 \%$ of baseline in the placebo group versus $50 \%$ in the ketotifen group. This sample size would provide $80 \%$ power at the 0.05 
significance level, assuming that the standard deviation is $40-42 \%$. Patients must have completed the study to be considered evaluable for the primary outcome variable.

Secondary outcome variables included FEV1, diary card data (symptom scores, PEFR diurnal variability, and number of doses of inhaled $\beta_{2}$-agonists irrespective of dosage or delivery system) and the logarithm of PC20. With respect to the diary card data, baseline was defined as the average of the daily values from weeks $-4-0$. For the 32 weeks of study treatment, average daily values were calculated for each 2 week period. These biweekly summaries were displayed graphically for review.

The primary outcome variable, the percentage of baseline ICS needed, was compared between the two treatment groups using Student's t-test. The Chi-squared test was performed to compare the proportion of patients who were withdrawn prematurely from the study. Baseline characteristics that were continuous and secondary outcome variables collected at the various time-points in the study were also compared using Student's t-test. All patients who remained in the study were compared. For categorical variables, the Chi-squared test was used except when the cell sizes were small, in which event Fisher's exact test was used. No adjustments were made for multiple comparisons.

Table 1. - Baseline characteristics by treatment groups

\begin{tabular}{|c|c|c|}
\hline Variable & $\begin{array}{c}\text { Ketotifen } \\
(\mathrm{n}=32)\end{array}$ & $\begin{array}{c}\text { Placebo } \\
(\mathrm{n}=34)\end{array}$ \\
\hline Age yrs & $8.7 \pm 2.1$ & $8.6 \pm 2.4$ \\
\hline Male gender \% & 72 & 56 \\
\hline Duration of asthma yrs & $5.8 \pm 2.6$ & $4.7 \pm 3.1$ \\
\hline Duration of ICS therapy yrs & $2.2 \pm 2.1$ & $1.9 \pm 1.6$ \\
\hline FVC \% pred & $95 \pm 13$ & $95 \pm 12$ \\
\hline FEV1 \% pred & $92 \pm 13$ & $95 \pm 15$ \\
\hline FEF25-75\% \% pred & $73 \pm 21$ & $83 \pm 24$ \\
\hline $\log \mathrm{PC}_{20} \mathrm{mg} \cdot \mathrm{mL}^{-1}$ & $-0.05 \pm 0.59$ & $-0.10 \pm 0.55$ \\
\hline \multicolumn{3}{|l|}{ Diary card data } \\
\hline Daily ICS dose $\mu \mathrm{g}$ & $432 \pm 260$ & $408 \pm 300$ \\
\hline Morning PEFR \% pred & $98 \pm 17$ & $103 \pm 19$ \\
\hline Evening PEFR \% pred & $100 \pm 17$ & $106 \pm 19$ \\
\hline Iorning symptom score & $0.19 \pm 0.25$ & $0.22 \pm 0.32$ \\
\hline Evening symptom score & $0.10 \pm 0.17$ & $0.13 \pm 0.26$ \\
\hline \multicolumn{3}{|c|}{ Concomitant medications (number of patients) } \\
\hline$\beta_{2}$-agonists & 28 & 31 \\
\hline Ipratr & 3 & 1 \\
\hline Theophylline & 1 & 2 \\
\hline
\end{tabular}

Values are presented as mean \pm SD. FVC, FEV1 and FEF25-75\% were measured at Week 0 . Log PC20 was measured at Week -4. Diary card data refer to mean daily values for weeks -4 to 0. ICS: inhaled corticosteroid; FVC: forced vital capacity; \% pred: percentage of predicted value; FEV1: forced expiratory volume in one second; $\mathrm{FEF} 25-75 \%$ : forced expiratory volume at mid-expiratory phase; $\mathrm{PC}_{20}$ : provocative concentration of methacholine producing a $20 \%$ fall in FEV1; PEFR: peak expiratory flow rate. $\mathrm{p}>0.05$ for all variables.

\section{Results}

Sixty six children entered the trial of whom 32 received ketotifen and 34 placebo. There was no seasonal difference in the two groups with respect to time of enrolment into the study. On entry into the study, there were no significant differences in the characteristics of the two groups (table 1). No differences were noted in the two groups with respect to abnormalities in haematological or biochemical tests at the beginning of the trial. Fourteen patients were withdrawn from the study (10 ketotifen and 4 placebo; $\mathrm{p}=0.053$ ), leaving 52 patients who completed the trial. Reasons for these withdrawals and the phase of the study at which they occurred are summarized in table 2.

\section{Corticosteroid reduction}

During the baseline period, there was no significant difference in the daily ICS dosage in the two groups of patients: the mean $(\mathrm{SD})$ dose in the ketotifen group was $432 \pm 260 \mu \mathrm{g} \cdot \mathrm{day}^{-1}$ (range $154-1,000 \mu \mathrm{g} \cdot \mathrm{day}^{-1}$ ) versus $408 \pm 300 \mu \mathrm{g} \cdot \mathrm{day}^{-1}$ (range 107-1,000 $\mu \mathrm{g} \cdot \mathrm{day}^{-1}$ ) in the placebo group. The ICS preparations being used by the patients were beclomethasone diproprionate $(n=55)$, flunisolide $(n=8)$ and budesonide $(n=3)$. Corticosteroid use, as recorded on the diary cards, declined progressively during the steroid-reduction phase of the study in both treatment groups (fig. 1). The reduction, however, was much greater than anticipated. Although the reduction among ketotifen patients was greater than that among the placebo patients, no statistically significant

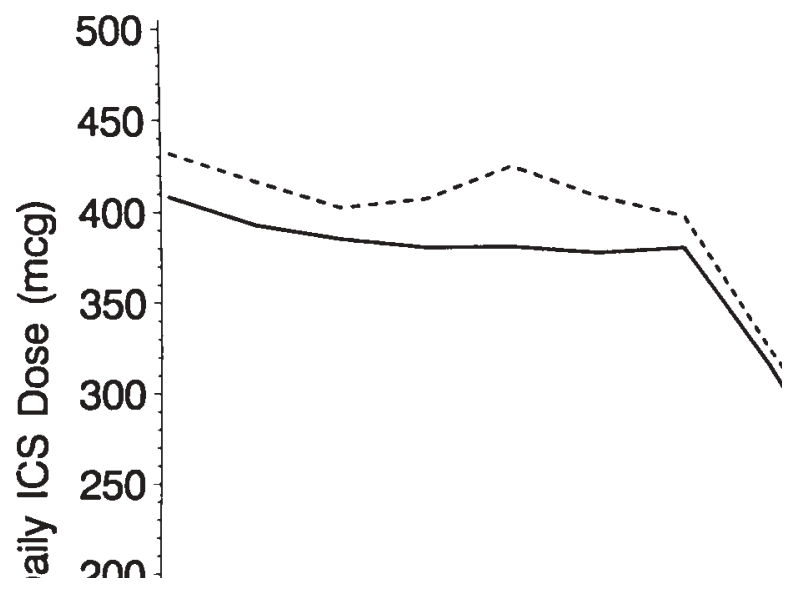

Fig. 1. - Average daily doses of inhaled corticosteroids (ICS) used by the two groups of patients, at baseline (BL) (week -4 to 0 ) and for every subsequent 2 week interval in the study. — : placebo; ….. : ketotifen.

Table 2. - Number of patients at each phase of study, and reasons for withdrawal

\begin{tabular}{|c|c|c|c|c|c|c|c|c|}
\hline \multirow[b]{3}{*}{ Study week } & \multicolumn{4}{|c|}{ Ketotifen } & \multicolumn{4}{|c|}{ Placebo } \\
\hline & \multirow[b]{2}{*}{$\begin{array}{c}\text { Pts } \\
\mathrm{n}\end{array}$} & \multicolumn{3}{|c|}{ Withdrawals } & \multirow[b]{2}{*}{$\begin{array}{c}\text { Pts } \\
\mathrm{n}\end{array}$} & \multicolumn{3}{|c|}{ Withdrawals } \\
\hline & & $\begin{array}{l}\text { Unstable } \\
\text { asthma }\end{array}$ & $\begin{array}{c}\text { Poor } \\
\text { compliance }\end{array}$ & $\begin{array}{l}\text { Side- } \\
\text { effects }\end{array}$ & & $\begin{array}{c}\text { Unstable } \\
\text { asthma }\end{array}$ & $\begin{array}{c}\text { Poor } \\
\text { compliance }\end{array}$ & $\begin{array}{l}\text { Side- } \\
\text { effects }\end{array}$ \\
\hline $1-12$ & 32 & 3 & 1 & 1 & 34 & 0 & 1 & 0 \\
\hline $13-20$ & 27 & 3 & 1 & 1 & 33 & 2 & 0 & 0 \\
\hline $21-32$ & 22 & 0 & 0 & 0 & 31 & 0 & 0 & 1 \\
\hline Completed study & 22 & & & & 30 & & & \\
\hline
\end{tabular}

Pts: patients. 

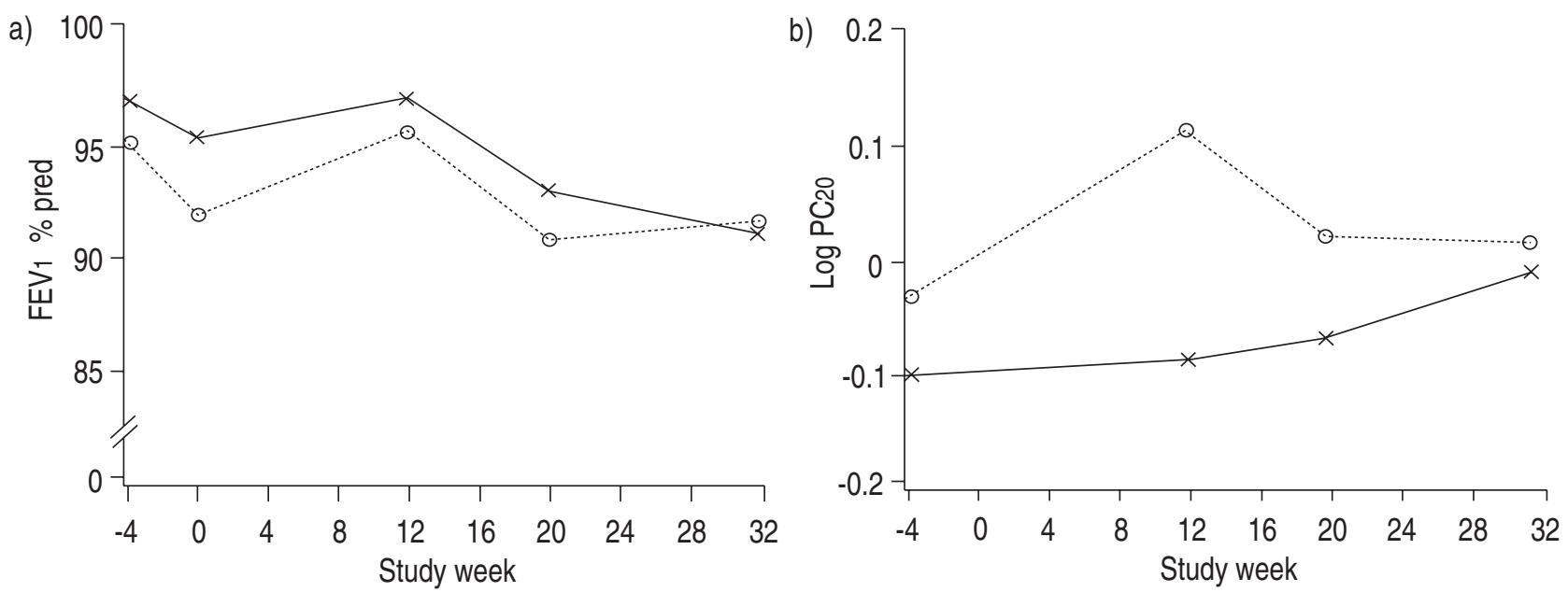

Fig. 2. - Mean values for: a) $\mathrm{FEV}_{1}\left(\%\right.$ pred); and b) $\log \mathrm{PC}_{20}$ methacholine, for the two groups of patients during the study. $\rightarrow-$ : placebo; $\cdots \circ$ : ketotifen. FEV1: forced expiratory volume in one second; PC20: provocative concentration of methacholine causing a $20 \%$ fall in $\mathrm{FEV}_{1} ; \%$ pred: percentage of predicted.

difference was found. Among the patients who completed the study, the average daily dose of ICS use during the follow-up phase was $18 \pm 34 \%$ of baseline in the ketotifen group as compared to $35 \pm 40 \%$ in the placebo group $(\mathrm{p}=0.121)$. At the end of the study, 17 of the 32 patients $(53 \%)$ in the ketotifen group had been completely withdrawn from ICS versus 12 of the 34 patients $(35 \%)$ in the placebo group $(\mathrm{p}=0.15)$.
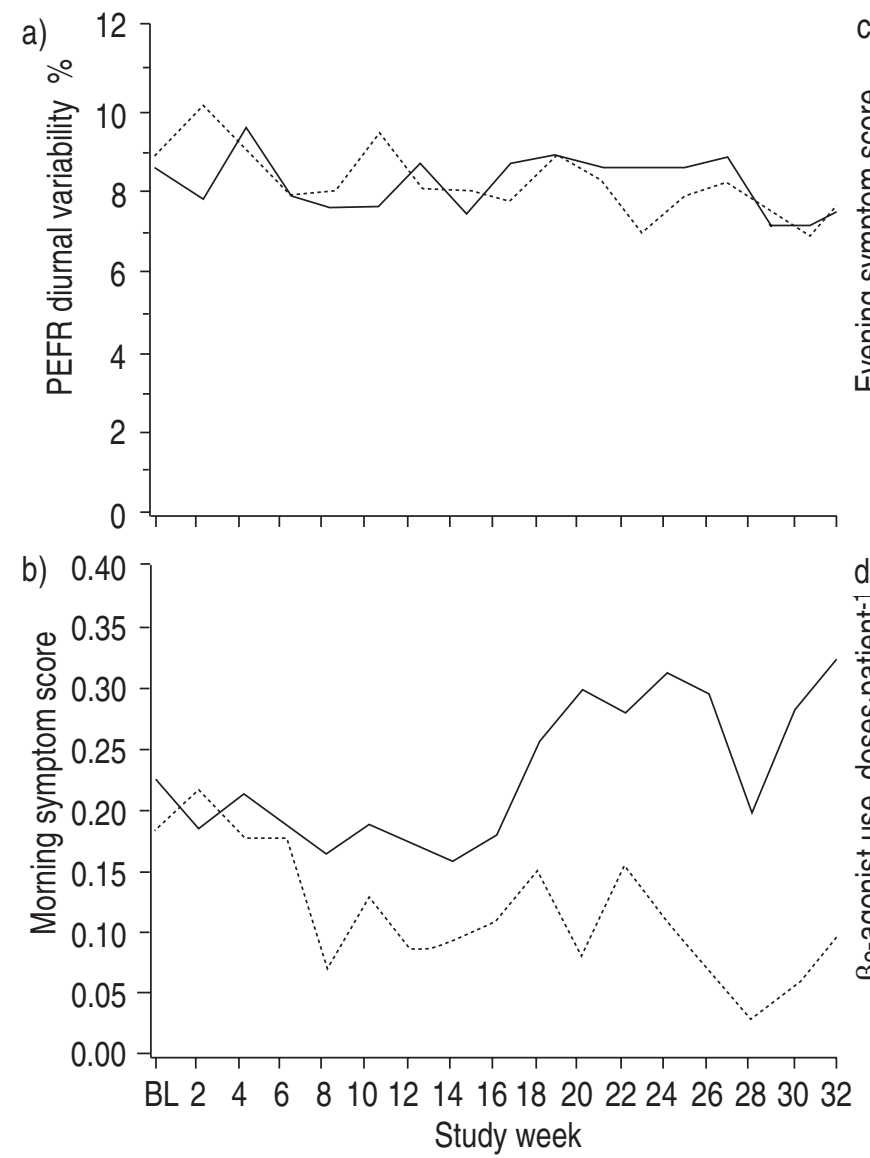

\section{Asthma control during the study}

On entry to the study, the children in both groups had well-controlled asthma, as attested by their symptom scores and spirometric measurements (table 1). With the exception of the eight patients who were withdrawn because of asthma exacerbations, this general trend continued throughout the study. As shown in figures 2 and
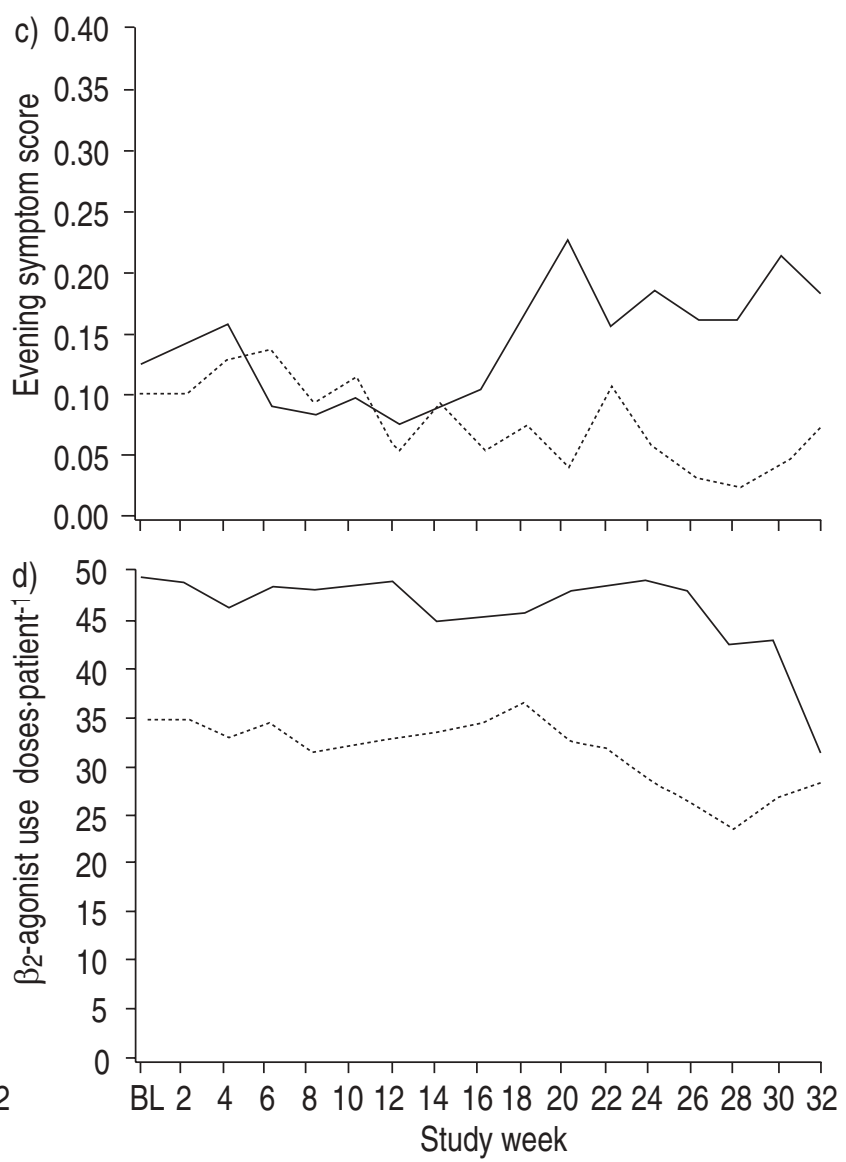

Fig. 3. - Mean daily values for: a) PEFR diurnal variability; b) morning symptom scores; c) evening symptom scores; and d) $\beta_{2}$-agonist use, at baseline (BL) and for every subsequent 2 week period in the study. _— : placebo; $\cdots \cdots . .$. : ketotifen. PEFR: peak expiratory flow rate. 
3, no significant differences were apparent over time between the two groups, with respect to FEV1, methacholine PC20 or the clinical variability in PEFR. However, significant differences were found between the two treatment groups with respect to morning and evening symptom scores (fig. 3). Among patients who remained in the study, the mean morning symptom scores during the follow-up phase (i.e. Weeks 21-32) were 0.09 \pm 0.1 and $0.28 \pm 0.34$, respectively, $(\mathrm{p}=0.015)$ for the ketotifen and placebo patients. The corresponding mean evening symptom scores were $0.06 \pm 0.07$ and $0.18 \pm 0.28$ ( $\mathrm{p}=0.046$ ). When adjusted for the baseline scores, these differences remained significant. Despite this, there was no statistically significant difference between the groups with respect to the use of $\beta_{2}$-agonists (fig. 3). During the follow-up phase (Weeks 21-32), five patients in the placebo group required courses of prednisone versus one patient in the ketotifen group.

\section{Adverse effects}

Thirty four percent of the ketotifen-treated patients and $27 \%$ of the placebo-treated patients (NS) complained of excess weight gain during the study. Although no significant differences were noted over time between the two groups with respect to body weight $(\mathrm{kg})$ or body mass index $\left(\mathrm{kg} \cdot \mathrm{m}^{-2}\right)$, the weight gained during the study was significantly greater in the ketotifen patients by 1 $\mathrm{kg}$ in body weight or $0.5 \mathrm{~kg} \cdot \mathrm{m}^{-2}$ in body mass index. Headache, increased appetite and sedation were reported by 13,5 and 2 patients, respectively, in the placebo group, and by 9,10 and 4 patients, respectively, in the ketotifen group (NS). One patient in the placebo group was withdrawn from the study because of recurrent headaches, and one patient in the ketotifen group because of excess weight gain. One other patient in the ketotifen group was withdrawn because of haematuria, which was unrelated to the trial medication. No differences were noted in the two groups with respect to abnormalities in haematological or biochemical tests at the end of the trial.

\section{Discussion}

The aim of the present study was to answer the clinical question as to whether ketotifen (versus placebo) might be used to replace or reduce ICS requirements in children, thereby minimizing the risk of adverse systemic effects from ICS preparations. The patients selected had a longstanding history of asthma, and had required ICS (for many years, in most cases) to maintain optimal asthma control. During the initial 12 weeks of treatment with ketotifen/placebo (i.e. Weeks 1-12) the patient's usual dose of ICS was maintained, as previous studies $[8,9]$ have shown that the maximum efficacy of ketotifen is only attained after 6-12 weeks of regular therapy. During the study, a high percentage of children both in the ketotifen- and placebo-treated groups were successfully weaned from ICS. Subsequent to the elimination or reduction in the need for ICS, spirometric parameters, and the degree of airway reactivity and need for beta $_{2}$-agonists remained stable until the end of the trial in both groups, although there was better control of daytime and night-time symptoms in favour of ketotifen. A significant use of $\beta_{2}$-agonists was noted in both groups throughout the study, which was not in keeping with the recorded symptom scores.

There are several possible explanations for these findings. It could be argued that the patients in this study were maintained on an unnecessarily high dosage of ICS, which might explain the significant steroid reduction that was achieved during the trial. Although ICS dosage in the study population had not been reduced according to a defined protocol prior to entry to the trial, the need for steroid therapy in these patients had been established historically over many visits to the clinic, where, as a matter of routine, regular attempts are made to reduce ICS dosage to a minimum. Likewise, the ICS dosage used by our patients at baseline is in keeping with current guidelines $[15,16]$, and based on the degree of reactivity to methacholine and the substantial need for $\beta_{2}$-agonists at baseline and throughout the study (fig. 2 ), it would appear that this dosage was not excessive. Another possible explanation for the reduced ICS needs during the study, is a substantial placebo effect, which has been well-documented in asthma trials [17]. Although there is no adequate explanation for this phenomenon it may be related to closer supervision, improved compliance and easier access to health care in the context of a clinical trial. Clearly, a reduction in steroid requirements achieved by closer clinical management is preferable to the addition of another antiasthma medication. Finally, the stability of asthma in our patient population subsequent to ICS weaning, may be related to a possible "carry-over" effect from prolonged inhaled steroid therapy.

In a group of adults, JUNIPER et al. [18] found that after 1 year of regular use, ICS could be safely withdrawn or reduced without an increase in airway reactivity or in bronchodilator needs during the ensuing 3 months. By that time, however, symptoms were beginning to redevelop and patients experienced a slight decline in spirometric measurements. Likewise, in a very recent study, HAAHTELA et al. [19] found that after a group of children with asthma had been treated with budesonide at a dose of $1,200 \mu \mathrm{g} \cdot \mathrm{day}^{-1}$ for 2 years, the dose of ICS could then be reduced to $400 \mu \mathrm{g} \cdot$ day $^{-1}$ in the majority of their patients without significant deterioration over the ensuing year. In contrast, complete discontinuation of ICS therapy often resulted in loss of asthma control [19]. In the present study, airway reactivity and lung function remained stable in both groups of patients for 12 weeks after ICS withdrawal/reduction, although the placebo-treated patients were more symptomatic during this period, observations that are in keeping with the data of JUNIPER et al. [18] and HAAHTELA et al. [19]. In contrast, other investigators [20-22] have found that the beneficial effects of ICS, in terms of control of symptoms, lung function and airway reactivity, are not maintained after cessation of therapy. There is no single explanation for the conflicting results of the aforementioned studies. However, it should be noted that there were differences in these studies with respect to duration and dose of prior ICS therapy, method of ICS withdrawal/discontinuation (i.e. abrupt versus gradual), concurrent use of $\beta_{2}$-agonists (i.e. intermittent versus regular) and, presumably, in patient characteristics. In addition, JUNIPER et al. [18] suggested that successful 
withdrawal of ICS is related to the degree of improvement in airway responsiveness to steroid therapy and to the final level of reactivity prior to weaning.

The relatively stable course of the majority of our patients during the study, precludes any definitive conclusions with respect to the efficacy (or lack thereof) of ketotifen in children with asthma. Symptomatically, the ketotifen-treated patients were better controlled during the final 12 weeks of this trial, although this may be a reflection of the higher withdrawal rate in the ketotifen group earlier in the study. Some previous trials have demonstrated the utility of ketotifen in asthmatic children $[8,9]$, with possible clinical efficacy equivalent to cromoglycate [23]. On the other hand, certain trials have yielded disappointing results with ketotifen, particularly in children with more severe asthma who are being treated concurrently with other prophylactic medications, cromoglycate or inhaled steroids [24]. It would appear, therefore, that ketotifen and ICS do not have a synergistic effect, although this does not necessarily imply that ketotifen is not worthwhile in children who are dependent on higher doses of ICS in order to facilitate a reduction in daily steroid storage.

In summary, the present study demonstrated that in the context of a clinical trial in children with moderately severe (but stable) asthma, a slow, carefully supervised reduction in dosage of inhaled corticosteroids was possible both in the ketotifen and placebo groups. During the final phase of the study, the ketotifen-treated group maintained better symptomatic control, although lung function parameters and the provocative dose of methacholine producing a $20 \%$ fall in forced expiratory volume in one second were not different in the two groups. This study underscores the importance of placebo-controlled studies to adequately interpret the role of new medications in a chronic disease, such as asthma. It also demonstrates, that the dose of inhaled corticosteroid can be grad-ually reduced in many children with asthma, thus minimizing the risk of systemic side-effects from inhaled steroids.

Acknowledgements: The authors thank Sandoz Canada Inc. for providing financial support for the study, A. Hall for co-ordinating the study, The John P. Robarts Research Institute (London Ontario) for statistical analysis and J. Chay for secretarial assistance.

\section{References}

1. Barnes PJ, Pederson S. Efficacy and safety of inhaled corticosteroids in asthma. Am Rev Respir Dis 1993; 148: S1-S26.

2. Geddes DM. Inhaled corticosteroids: benefits and risks. Thorax 1992; 47: 404-407.

3. Nicolaizik WH, Marchant JL, Preece MA, Warner JO. Endocrine and lung function in asthmatic children on inhaled corticosteroids. Am J Respir Crit Care Med 1994; 150: 624-628.

4. Toogood JX, Jennings B, Lefcoe NM. A clinical trial of combined cromolyn/beclomethasone treatment for chronic asthma. J Allergy Clin Immunol 1981; 67: 317-324.

5. Bone MF, Kubik MM, Keaney NP, et al. Nedocromil sodium in adults with asthma dependent on inhaled corticosteroids: a double-blind, placebo-controlled study. Thorax 1989; 44: 654-659.
6. Goldin JG, Bateman ED. Does nedocromil sodium have a steroid-sparing effect in adult asthmatic patients requiring maintenance oral corticosteroids? Thorax 1988; 43: 982-986.

7. Paananen M, Karakorpi T, Krem KE. Withdrawal of inhaled corticosteroid under cover of nedocromil sodium. Eur J Respir Dis 1986; 69: 330-335.

8. Rackham A, Brown CA, Chandra RK, et al. A Canadian multicenter study with Zaditen (ketotifen) in the treatment of bronchial asthma in children age 5-17 years. $J$ Allergy Clin Immunol 1989; 84: 286-296.

9. Simons FER, Luciuk GH, Becker AB, Gillespie CA. Ketotifen: a new drug for prophylaxis of asthma in children. Ann Allergy 1982; 48: 145-150.

10. Lane DJ. A steroid-sparing effect of ketotifen in steroiddependent asthmatics. Clin Allergy 1980; 10: 519-525.

11. Dyson AJ, MacKay AD. Ketotifen in adult asthma. $\mathrm{Br}$ Med J 1980; 1: 360-361.

12. Weng T-R, Levison H. Standards of pulmonary function in children. Am Rev Respir Dis 1969; 99: 879-894.

13. American Thoracic Society. Standardization of spirometry: 1987 update. Am Rev Respir Dis 1987; 136: 12851298.

14. Amaro-Galvez R, McLaughlin FJ, Levison $\mathrm{H}$, et al. Grading severity and treatment requirements to control symptoms in asthmatic children and their relationship with airway hyperreactivity to methacholine. Ann Allergy 1987; 59: 298-302.

15. National Asthma Education Program Expert Panel Report. Executive Summary: Guidelines for the Diagnosis and Management of Asthma. Bethesda, Md, National Institutes of Health, 1991; US Dept of Health and Human Services publication No. 91-3042A.

16. Warner JO, Neijens HJ, Landeu, et al. Asthma: followup treatment from an international pediatric asthma consensus group. Arch Dis Child 1992; 67: 240-248.

17. Reiser J, Warner J. The value of participating in an asthma trial. Lancet 1985; 1: 206-207.

18. Juniper EF, Kline PA, Vanzieleghem MA, Hargreave FE. Reduction of budesonide after a year of increased use: a randomized controlled trial to evaluate whether improvements of airway responsiveness and clinical asthma are maintained. J Allergy Clin Immunol 1991; 87: 483-489.

19. Haahtela T, Jarvinen M, Kara J, et al. Effects of reducing or discontinuing inhaled budesonide in patients with mild asthma. N Engl J Med 1994; 331: 700-705.

20. Waalkens HJ, Van Essen-Zandvliet EE, Hughes MD, et al. Cessation of long-term treatment with inhaled corticosteroid (budesonide) in children with asthma results in deterioration. Am Rev Respir Dis 1993; 148: 1252-1257.

21. Kraan J, Koëter GH, Van der Mark TW, Sluiter HJ, de Vries K. Changes in bronchial hyperreactivity induced by 4 weeks treatment with antiasthmatic drugs in patients with allergic asthma: a comparison between budesonide and terbutaline. J Allergy Clin Immunol 1985; 76 : 628-636.

22. Vathenen AS, Knox AJ, Wisniewski A, Tattersfield AE. Time course of change in bronchial reactivity with an inhaled corticosteroid in asthma. Am Rev Respir Dis 1991; 143: 1317-1321.

23. Graaf-Lonnevig V, Kusoffsky E. Comparison of the clinical effect of ketotifen and DSCG in pollen-induced childhood asthma. Allergy 1980; 35: 341-348.

24. Loftus BG, Price JF. Long-term, placebo-controlled trial of ketotifen in the management of preschool children with asthma. J Allergy Clin Immunol 1987; 79: 350-355. 